\title{
Crew Resource Management and its possible role in nursing risk management
}

\author{
I. R. McAndrew ${ }^{1}$ \& G. P. Wise ${ }^{2}$ \\ ${ }^{1}$ Embry Riddle Aeronautical University, USA \\ ${ }^{2}$ Southampton Trust Hospital, UK
}

\begin{abstract}
Crew Resource Management (CRM) was introduced within the aviation industry in the late 1970s after an aircraft ran out of fuel whilst the pilots were trying to solve an undercarriage problem. To reduce such errors and ultimately lower the probability of failure and the severity of risks that occur, training in CRM was rolled out across the whole industry. It has been successful over the last few years in major reductions in the number of crashes and fatalities in the commercial aviation sector. Nursing has similar concerns in that errors can ultimately result in fatalities [1]. There are parallels in the needs and expectations of pilots and nurses to assess risk, reduce risk and deliver reliable and dependable professional services. In this paper the parallels of pilots and nurses demands are compared to assess if the lessons learned in aviation can assist nurses deliver procedures with lower risks. The analysis will draw on the demands and expectations and how they both deal with risk, challenging errors and ensuring that identified risks are not overlooked or ignored [2]. Finally, suggestions of adopting, sharing and benchmarking between these two industries can adopt best practices so that both industries can learn from each other.
\end{abstract}

Keywords: Crew Resource Management, nursing, error reduction.

\section{Introduction}

The aviation industry has an extensive history of errors, mishaps, accidents and disasters that stretch back before the first powered flight by the Wright Brothers in 1903. These have been on small scale up to the world's highest fatality in the Tenerife disaster of 1977 when 583 people died in one accident. This disaster occurred due to human error when one pilot made the decision that the fog 
bound runway was clear for take-off whilst not knowing that Air Traffic Control had given permission to taxi on the runway. The result was a collision at speed when one B-747 accelerating down the runway hit another B-747 taxing. The subsequent investigation highlighted several errors and mistakes that had happened, with the primary reason being human error and confusion.

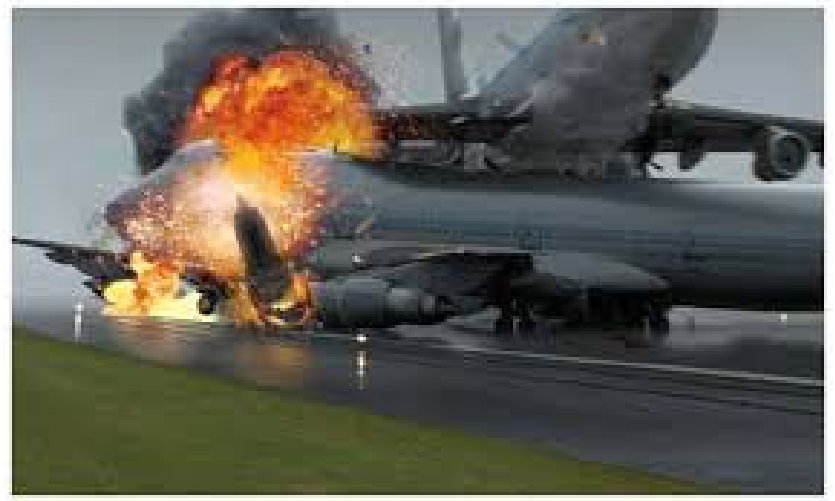

Figure 1: Simulated image of impact between the two B-747s.

Aviation has many examples of things gone wrong and the advantage of this industry is that it has systems in place to learn by its mistakes [3]. This Tenerife incident brought about a quantum shift in the training of pilots, air traffic controllers and personal involved with the safe operations of flight.

Below in figure 2 it shows the number of hull (total) loses from the 1940s until present day. This clearly shows the increases that occurred up until the 1970 s, when there has been a steady trend downwards. Given that this represents the industry as a whole there needs to be a clear explanation of what this graphs shows and does not show [4]. Accidents occur for a variety of reasons, with the most prominent ones being: human error, mechanical and weather conditions. The increase in commercial aviation increased post World War II and that also increased the probability of accidents pro rata up to the 1970s. Passenger numbers have increased almost exponentially since the 1980s; however, the accident rate per flying hour has reduced over this period. It is statistically true to say that flying is now safer than any time before. The exact reasons are complex and one single action can claim its success [5]. Design theory is better, computers to simulate and maintenance practices that are robust and internationally accepted all assist in the reduction of accident. The principal reason of any crash is still human error, whether a mistake, not accommodating for weather conditions or lack of training or knowledge. The Tenerife accident ignited the governing bodies around the world to identify deficiencies in training and this started the subject of Crew Resource Management (CRM). It can be argued this was the seminal moment when the aviation industry realised that substantial responsibility was required to ensure the likelihood of any accident was always at its minimum. 


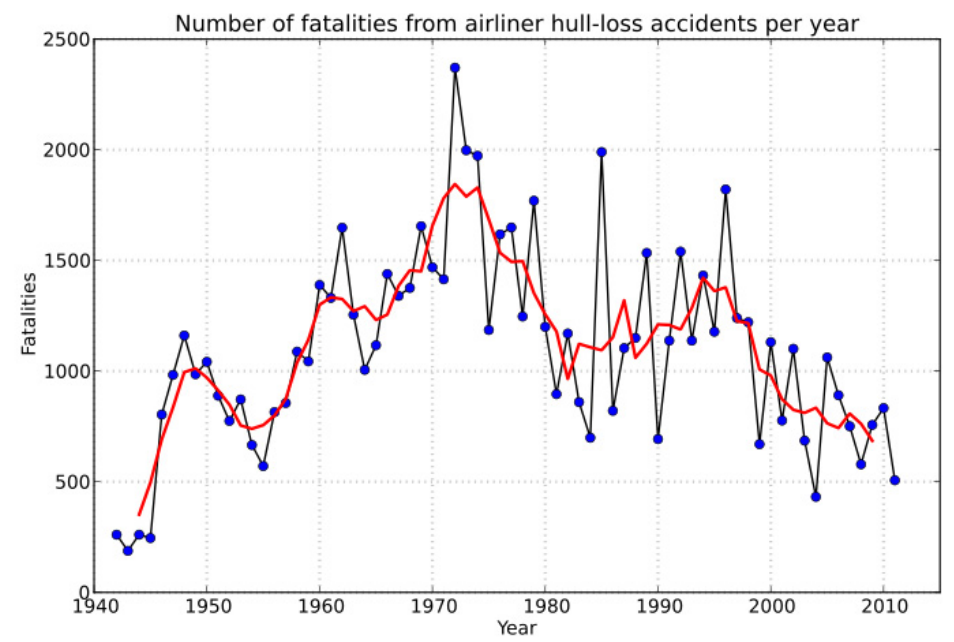

Figure 2: Number of fatalities from airliners (14+ passengers) hull loss accidents per year. In red is the 5-year average.

Figure 3 it shows the trend of accidents, reported per 100,000 hours of flying. This trend is represented alike in both Europe, North America. Regardless of what are the reasons why there is a reduction it is continuing to make aviation the safest form of transport [6]. It is worth noting that the percentage of categories assigned to the cause of an accident have not significantly changed in the past 50 years, only the number of incidences. It will be argued by many that $\mathrm{CRM}$ is a significant influence on this continuing improvement.

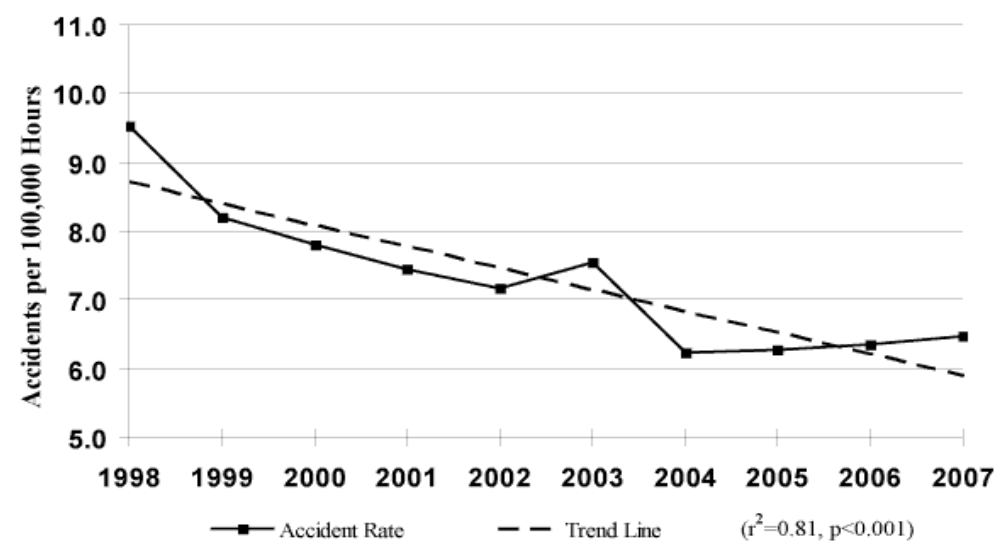

Figure 3: Accident rates per 100,000 flying hours. 
Reasons for accidents apart from runway hazards can all be related to CRM and the ineffective use of communications. The International Civil Aviation Organisation (ICAO) in 1944 at the Chicago convention designated that English will be the universal language for aviation. Thus, any international flights must use English for communication between Air Traffic Controllers (ATC) and other communication links. Therefore, the majority of pilots flying outside of their home county will be using English as a second language. Using that point half of the reasons listed in Table 1 will involve a translation into a second language.

Table 1: $\quad$ Percentage breakdown of principal reasons attributable to aviation accidents.

\begin{tabular}{|l|l|}
\hline Reason for Accident & $\mathbf{\%}$ \\
\hline $\begin{array}{l}\text { Pilot deviated from basic operational } \\
\text { procedures }\end{array}$ & $33 \%$ \\
\hline $\begin{array}{l}\text { Inadequate cross-check by second crew } \\
\text { member }\end{array}$ & $26 \%$ \\
\hline Design faults & $13 \%$ \\
\hline Maintenance and inspection deficiencies & $12 \%$ \\
\hline Absence of approach guidance & $10 \%$ \\
\hline Captain ignored crew inputs & $10 \%$ \\
\hline Air traffic control failures or errors & $9 \%$ \\
\hline $\begin{array}{l}\text { Improper crew response during abnormal } \\
\text { conditions }\end{array}$ & $9 \%$ \\
\hline Insufficient or incorrect weather information & $8 \%$ \\
\hline Runways hazards & $7 \%$ \\
\hline $\begin{array}{l}\text { Air traffic control/crew communication } \\
\text { deficiencies }\end{array}$ & $6 \%$ \\
\hline Improper decision to land & $6 \%$ \\
\hline
\end{tabular}

CRM is a concept of operation and how people work together (Diehl [1]). Its concepts are based on cognitive and interpersonal skills needed to manage resources in an organisation, between organisations and between people. The key word is communication. Communication between all involved in a flight and effective ways of maintaining a professional standing is the fundamental focus [7]. For example, telling someone does not mean they understand the task given. There may be a variety of reasons why it was not understood: language, clarify of description, inflection in the voice, etc.

Assumptions are made by those that give information and those that receive information. In figure 4 below it shows how items may be identified, look closely at B and 13 . When the letter B is read in conjunction with other letters it may be very easy to identify, when read in conjunction with numbers there are concerns. Of course dyslexia, colour blindness and if any visual impairments can result in errors, likewise audible clarity cannot easily be determined in crash investigations if English is not spoken clearly. This is compounded when the strength of radio communication is affected by background electronic noise, etc. 


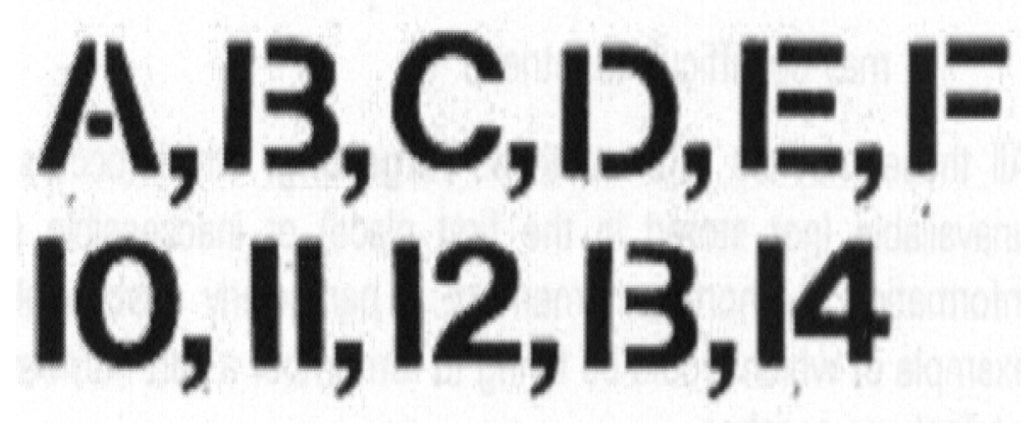

Figure 4: Ways items can be identified.

Human factors in CRM has developed a method known as the SHEL model. This is a method where the human is seen as the middle interface [8]. It can be helpful to use a model to aid in the understanding of human factors, or as a framework around which human factors issues can be structured. A model, which is often used is the SHEL model, a name derived from the initial letters of its components:

- Software (e.g. maintenance procedures, maintenance manuals, checklist layout, etc.)

- Hardware (e.g. tools, test equipment, the physical structure of aircraft, design of flight decks, positioning and operating sense of controls and instruments, etc.)

- Environment (e.g. physical environment such as conditions in the hangar, conditions on the line, etc. and work environment such as work patterns, management structures, public perception of the industry, etc.)

- Liveware (e.g. the person or people at the centre of the model, including maintenance engineers, supervisors, planners, managers, etc.)

- Human factors concentrates on the interfaces between the human (the ' $L$ ' in the centre box) and the other elements of the SHEL model, and (from a safety viewpoint) where these elements can be deficient, e.g.:

S: Misinterpretation of procedures, badly written manuals, poorly designed checklists, untested or difficult to use computer software

H: Not enough tools, inappropriate equipment, poor aircraft design for maintainability

E: Uncomfortable workplace, inadequate hangar space, extreme temperatures, excessive noise, poor lighting

L: Relationships with other people, shortage of manpower, lack of supervision, lack of support from managers.

Man - the 'Liveware' - can perform a wide range of activities. 


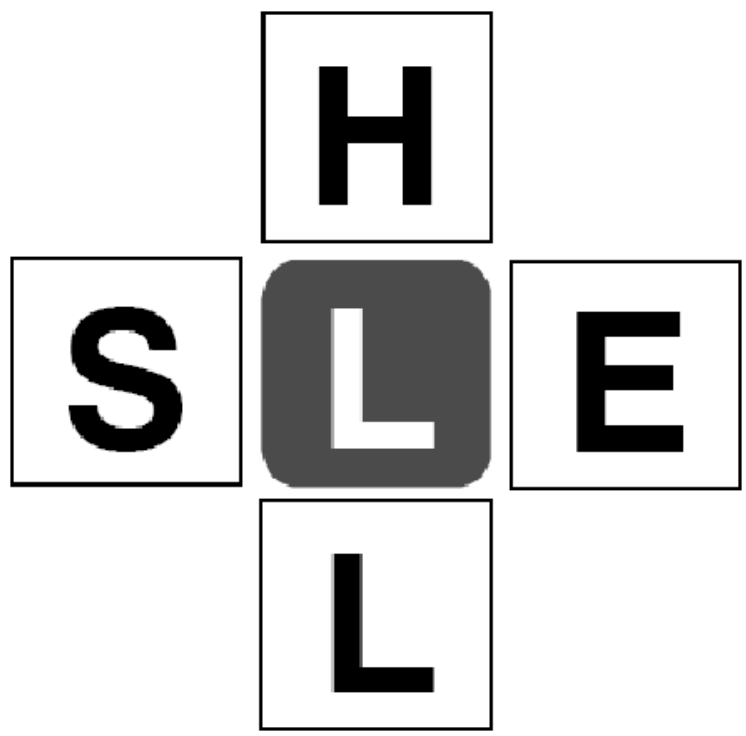

Figure 5: The SHELL model for interfacing with systems.

Affective CRM is meant to be there for all instances, but perhaps the most critical is when there is a difference in experiences. A junior co-pilot flying alongside an experienced Captain might feel intimidated to say if something is not right for fear of being wrong, rebuffed or over-crossing a professional line. This can be compounded when dealing with military and their ranks or in cultures where age is seen as experience and to challenge is disrespectful [9]. Such situations can occur in nursing, a junior nurse dealing with an experienced ward manager or in an operating theatre with a senior consultant are examples.

\section{Nursing practices}

Nursing no longer has the historical image of ladies helping keep wards clean and making beds before handing out the medicine. It has evolved extensively since the 1990s to be a degree based discipline that specialises with high tech equipment and interfacing with many different medical disciplines [10]. Theatre nursing, midwifery and intensive care nursing often involve dealing with senior medical doctors and surgeons. Likewise, they have a hierarchy where junior or newly qualified staff is under the same peer pressures as pilots and aircraft maintainers. Peer pressure, the possibility of identifying errors under the fear of embarrassment is a risk in nursing equal to those of the aviation industry. There are many incidences where injury and death have resulted from mistakes not being identified and others failing to comment due to peer pressures at work [11]. There are parallels with the aviation industry that can be used as benchmarking for reducing the likelihood of mistakes to patients and the patent care process. 
Anesthetic care was studied for mishaps, errors and mistakes and this extensive study produced the following classifications listed below. In such an environment where time is critical, pressure of failure and dealing with relatives, etc, add major input concerns that compound to result in potential disasters. Below in the table shows the result from one such study [12]. This list is representative of errors experienced in the aviation maintenance sector (Current Anaesthesia and Critical Care, 1995 [22]). Human error accounts for the principal reasons for a problem. Nursing that covers 24 hours a day for 365 days in a year can be paralleled with aviation maintenance and pilots/ATC work patterns. It cannot be over emphasised the parallels that compare between these two different but allied worlds of pressure and expectations. Each of these failures apart for the $10^{\text {th }}$ and $12^{\text {th }}$ have been a cause many aircraft accidents [13]. If proven and effective ways are readily available in other sectors then it is difficult to argue against minimising risks by employing them in the hospital environment.

Table 2: Classifications for aesthetic errors.

\begin{tabular}{|l|c|}
\hline \multicolumn{1}{|c|}{ Failure } & Percentage \\
\hline Misjudgement & 16 \\
\hline Failure to check equipment & 13 \\
\hline Fault of technique & 13 \\
\hline Other human factors problems & 13 \\
\hline Other equipment problem & 13 \\
\hline Inattention & 12 \\
\hline Haste & 12 \\
\hline Inexperience & 11 \\
\hline Communication problem & 9 \\
\hline Inadequate preoperative assessment & 7 \\
\hline Monitor problem & 6 \\
\hline Inadequate preoperative preparation & 4 \\
\hline
\end{tabular}

Medication errors have been shown to be as high as $11 \%$ of patient incidents, (National Reporting and Learning System, 2012 [20]) in England and Wales between June 2010 and June 2011. Although, approximately $90 \%$ of the 100,000 plus incidents that were reported caused no noticeable harm to patients, 253 resulted in problems that required further emergency medical intervention and over 50 deaths. Such medication errors are most likely to be attributable to the wrong dose, omitted or delayed medication or the wrong medication (National Patient Safety Agency, 2009 [20]). There is no established method universally adopted for minimising risk in medication errors. A computer based recording and monitoring system cannot mitigate the effects from pressure, shift work and tiredness. Within aviation there are limits in time worked as to when procedures can be informed, for example, limiting the time a pilot can fly or be on standby. This subject, above all else, is where human factors and training for the 'dirty dozen' (the most common classifications of errors, mishaps and mistakes) could 
be argued to have the biggest impact in reducing the risk of errors in administering drugs. Each year in aviation every maintainer must undertake a training course in human factors, similar to CPR or child protection training. If not completed and the assessment passed they are prevented from working on any aircraft. Evidence has paralleled its introduction and reduction in errors, mishaps and mistakes [14].

The most frequently cited wrong-dose error results from a calculation error. A major drive by the NHS has been to remove these by trying different approaches. In figure 6 below is one such attempt. Will wearing such a top stop errors, remove people interrupting? It is as if stating speed limit signs will slow drivers speed. A system approach of CRM is needed to make inroads into this problem and minimise risk [15]. Effective drug administration must be managed in a system approach and continuous training is at the very core of reducing risks.

CRM is more than training, it is equipping people with the skills, ability and confidence to undertake a job function professionally and deal with extreme situations that may not have been covered in training. Furthermore there are individual techniques that are discussed below to assist in detail risk evaluation and error removal. No one technique or procedure will ever remove risk; several in series will collectively conflate the efforts to result in very low probabilities of errors [16]. If the SHELL model is applied to this process and think of the middle as the nurse, the $\mathrm{S}$ (software) will be the electronic recording, $\mathrm{H}$ (Hardware) the container, recording method, E (environment) lighting level, and finally L (Liveware) those other professionals sharing the task. All have to be effective for the success, but each person can recognise if any mishap, error or omission.

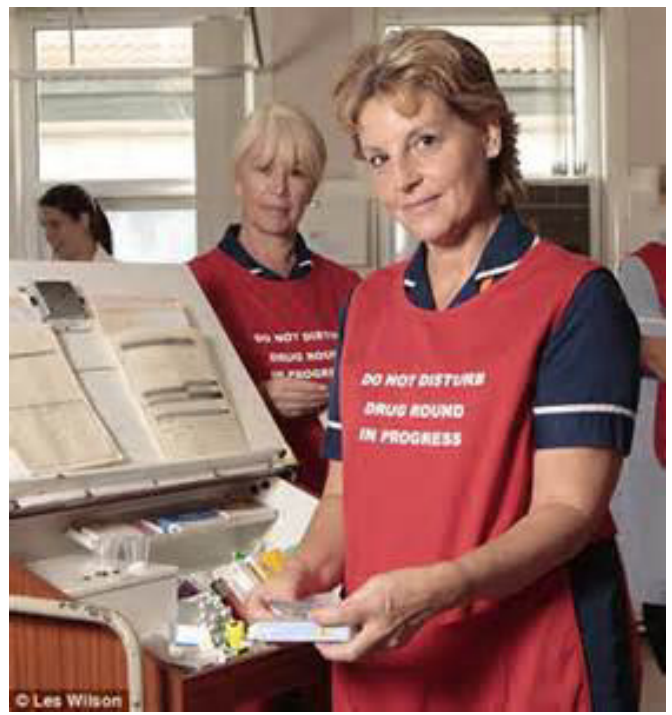

Figure 6: Drug error reduction procedure. 
There are numerous parallels between the aviation and nursing sectors. Clearly there are lessons that can be learned and applied to integrate human factors into the nursing profession. It could be to implement human factor training and yearly follow ups as required for other techniques, e.g., lifesaving. However, we need to evaluate risk. More specifically, reducing risk of an error occurring. Here the suggestion is the Swiss Cheese Method.

The principle behind this model can be considered in reverse. For a hazard to result in an error occurring the individual stages that contribute must align, for example, the medication dose is unclear, pressure to administer, distractions when calculation dosage [17]. When these all happen then the wrong dosage will be delivered. This method is to review each stage that can go wrong, add individual procedures to minimise and do the same for each stage. Thus, collectively the likelihood reduces for a total system failure.

This model can be applied to drug rounds [18, 19]. The staff trained and records kept, yearly up dates, sufficient time, and correct information coupled with all associated equipment to administer, record and document. Each one is a barrier, collectively they are a more robust barrier to minimise risk. These methods add to those of conventional risk analysis, as Failure Mode Effects Analysis (FMEA), which will evaluate the probability of a risk. Here, CRM is not interested in the actual probability of a failure but that procedures will add layer after layer to reduce the possibility [20]. The ultimate probability of any failure will be linked to the probability of the severity, the occurrence and detection. If not severe and unlikely to occur it could be argued the detection system can be basic [21]. Alternatively, if moderate in severity and a common occurrence then a robust detection system is needed. Balancing systems is more detailed than just reviewing the severity of a problem.

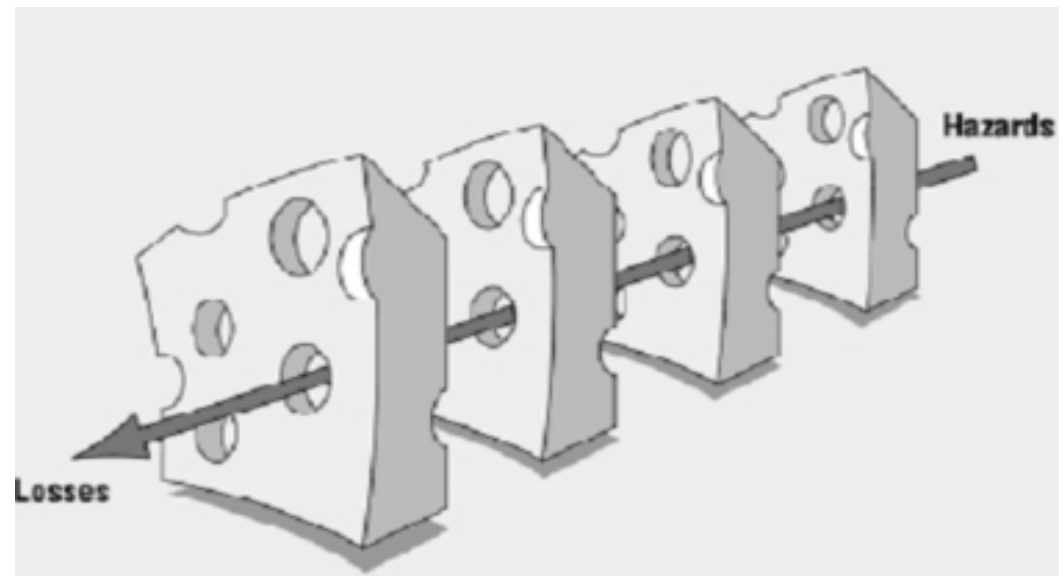

Figure 7: A representation of the principal approach. Only when all the risks occur will the end result be a failure, omission, mishap or disaster. 


\section{Conclusions}

This paper has addressed the need and development of human factors in the aviation industry and how Crew Resource Management has evolved for Pilots, Air Traffic Controllers and maintainers. These techniques can be exploited within the nursing and medical industry where numerous parallels can be drawn. These parallels of peer pressure, life pressures, life and death situations where problems can occur that are unique and require expert intervention. If we want to reduce risks in nursing there is no need to invent new solutions, we can use the tried and trusted methods that has served the aviation well during the last three decades.

\section{References}

[1] Diehl, Alan (1994): Crew Resource Management...It's Not Just for Fliers Anymore. Flying Safety, USAF Safety Agency.

[2] Johnson, W. B., Hall, S., Watson, J., (2001). "Evaluation of Aviation Maintenance Working Environments, Fatigue and Human Performance". Retrieved from http://www.hf.faa.gov/hfportalnew/Search/ DOCs/EvaluationofAviationMaintenanceWorkingEnvironmentFatigueand HumanPerformance.pdf

[3] International Civil Aviation Organization. (2009). Safety Management Manual (9859 AN/474). Montreal, Canada: International Civil Aviation Organization.

[4] Mulenburg, J. (2009). Crew resource management improves decision making. Retrieved from http://www.nasa.gov/offices/oce/appel/ask/issues/ 42/42i_crew_resource_management_prt.htm

[5] Chalkley, J. (2013). Medical assessment of the older commercial pilot: why, what and when? Aviation, Space, and Environmental Medicine, 84(4), 332. http://search.proquest.com.ezproxy.libproxy.db.erau.edu/ docview/1356929018? accountid=27203

[6] Cornell, A., Baker, S. P. \& Li, G. (2007). Age-60 rule: the end is in sight. Aviation, Space, and Environmental Medicine, 78(6), 624-626. Retrieved from http://search.proquest.com.ezproxy.libproxy.db.erau.edu/docview/ 29980759? accountid=27203

[7] Federal Aviation Administration. (2002). AC 120-66B - Aviation Safety Action Program (ASAP). Retrieved from http:/www.faa.gov/regulations policies/advisory_circulars/index.cfm/go/document.information/document ID/23207

[8] Smith, G. M. (1994). Evaluating self-analysis as a strategy for learning crew resource management $(\mathrm{CRM})$ in undergraduate flight training. Ed .D., Montana State University, http://search.proquest.com/docview/ 304115656? accountid=27203

[9] Stolzer, A. J., C. D. Halford and J. J. Goglia. 2008. Safety management systems in aviation. Burlington, VT: Ashgate. 
[10] Landrigan, C.P., (2010) Temporal Trends in Rates of Patent Harm Resulting from Medical Care, New England Journal of Medicine.

[11] Levinson, D. R. (2010) Adverse Events in Hospitals: National Incidence Among Medicare Beneficiaries, Department of Health and Human Services Office of the Inspector General.

[12] Gaba DM. Human error in dynamic medical domains. In: Bogner MS, ed. Human errors in medicine. Hillsdale, NJ: Erlbaum, 1994.

[13] Wilson M. Errors and accidents in anaesthetics. In: Vincent C, Ennis M, Audley R, eds. Medical accidents. Oxford: Oxford University Press, 1993: 61-79.

[14] Williamson JA, Webb RK, Sellen A, et al. Human failure: an analysis of 2000 incident reports. Anaesth Intens Care 1993; 21: 678-83.

[15] Weir PM, Wilson ME. Are you getting the message? A look at the communication between the Department of Health, manufacturers and anaesthetists. Anaesthesia 1991; 46: 845-848.

[16] Alsulami Z et al. (2012) Double checking the administration of medicines: what is the evidence? A systematic review. Archives of Disease in Childhood. doi:10.1136/archdischild-2011-301093 online tinyurl.com/ doublechkmeds

[17] Nursing and Midwifery Council (2010) Standards for Medicine Management. London: www.NMC.tinyurl.com/nmc-meds.

[18] National Patient Safety Agency (2010) Safer Administration of Insulin. www.tinyurl.com/nrlssafetyinsulin National Patient Safety Agency (2009a) Safety in Doses: Improving the Use of Medicines in the NHS. www.tinyurl.com/nrlssafetydoses

[19] National Patient Safety Agency (2009b) Review of Patient Safety for Children and Young People. www.tinyurl.com/nrlssafetychild.

[20] National Reporting and Learning System (2012) Quarterly Data Workbook up to September 2011. www.tinyurl.com/nrlsquartmar12

[21] Wright K (2008) Why do we teach the nursing drug calculation formula to Calculate drug dosages? Nursing Standard; 22: 36, 40-42.

[22] Current Anaesthesia and Critical Care 1995, Volume 6, pages 121-126. 